\title{
How Children Move: Activity Pattern Characteristics in Lean and Obese Chinese Children
}

\author{
Alison M. McManus, ${ }^{1}$ Eva Y. W. Chu, ${ }^{2}$ Clare C. W. Yu, ${ }^{1}$ and Yong $\mathrm{Hu}^{3}$ \\ ${ }^{1}$ Institute of Human Performance, The University of Hong Kong, Pokfulam Road, Pokfulam, Hong Kong \\ ${ }^{2}$ Department of Medicine, The University of Hong Kong, Pokfulam, Hong Kong \\ ${ }^{3}$ Department of Orthopaedic Surgery, The University of Hong Kong, Pokfulam, Hong Kong \\ Correspondence should be addressed to Alison M. McManus, alimac@hku.hk
}

Received 1 June 2010; Revised 1 September 2010; Accepted 2 December 2010

Academic Editor: Eric Doucet

Copyright (๑) 2011 Alison M. McManus et al. This is an open access article distributed under the Creative Commons Attribution License, which permits unrestricted use, distribution, and reproduction in any medium, provided the original work is properly cited.

\begin{abstract}
Physical activity and sedentary behavior are central components of lifetime weight control; however, our understanding of dimensions of these behaviors in childhood is limited. This study investigated free-living activity pattern characteristics and the individual variability of these characteristics in 84 lean and obese Chinese children (7-9y) during the school day and over the weekend. Activity pattern characteristics were established from triaxial accelerometry (StayHealthy RT3). Results indicated that children's free-living activity is characterized by many short-duration, low-intensity bouts of movement. Obese children take longer rest intervals between bouts and engage in fewer activity bouts both at school and at home. Intraindividual variability in activity patterns was low during school days but high for the rest intervals between bouts and number of activity bouts per day at the weekend. Finding ways to reduce the rest time between bouts of movement and increase the number of movement bouts a child experiences each day is an important next step.
\end{abstract}

\section{Introduction}

Children do not voluntarily engage in sustained periods of constant intensity physical activity [1]. Instead, early evidence characterizing spontaneous physical activity in children has shown that children take frequent ( 83 to 89 bouts per hour), short-duration (mean duration of 20 to 21 s) bouts of movement of variable but mostly low intensity, interspersed by comparatively long intervals of nonactive time $[2,3]$. This pattern of movement was termed the "tempo" of physical activity, that is, the frequency with which an activity event occurs and the intervals between these [2]. It has been suggested that these pattern characteristics may be physiologically more important than composite measures of physical activity. For instance, dynamic heart rate recovery times [4] were noted to be of similar length to the nonactive intervals between bouts of movement [2] More recent evidence has shown that bouts of movement were shorter and less intense in overweight compared to lean boys [5]. Evidence from spontaneous walking in adults has also shown that the duration of each walking bout resulted in obese adults walking about $2 \mathrm{hrs}$ per day less than the lean, equivalent to approximately 3.5 fewer miles walked per day [6]. In the same study, participants were overfed for a period of 8 weeks resulting in weight gain and a decrease in the distance walked per day in the obese, suggestive of a mechanistic link between obesity, weight control, and spontaneous physical activity.

Whereas various social, psychological, and environmental factors have been shown to explain interindividual differences in childhood physical activity levels [7], intra-individual variation in free-living movement enables scrutiny of the extent to which physical activity is under biological control [8]. Available data suggests that total physical activity shows low intra-individual variation, with values between 20 and $25 \%$ in both children and adults [9, 10]. Similarly, a lack of variation in daily physical activity in response to changes in the physical environment in children has been used to support the argument that there is a physical activity phenotype [11]. 
What is not known is the degree to which the tempo of spontaneous physical activity varies within a child and how the tempo of physical activity differs with weight status. The primary objective of this study, therefore, was to provide information on the pattern characteristics of physical activity in lean and obese girls and boys during the school day and over the weekend and the intra-individual variation in these. Specifically, we hypothesized that (i) lean children would have more frequent and intense movement bouts and shorter intervals between these in comparison to the obese, independent of sex and location (school versus home); (ii) intra-individual variability in the pattern characteristics of physical activity would be similar in the lean and obese, independent of sex and location. To achieve this, we utilized cluster recognition algorithms to characterize the tempo of physical activity from second-by-second triaxial accelerometer output. The algorithms are based on the work of Veldhuis and Johnson [12], which were originally used to characterize the pulsatile patterns of hormone release but have since been used to identify activity pattern characteristics [3].

\section{Materials and Methods}

2.1. Participants. Chinese children aged 7 to 9 years were recruited from three government primary schools in Hong Kong. From a potential of 6007 - to 9-year olds, 180 volunteered to participate. Height and weight were assessed in school in all 180 pupils, and those above the 90th percentile for age- and sex-specific BMI cutoffs [13], as well as a group of age- and sex-matched lean children, were invited to join the study. Eighty-four children (42 lean and 42 obese, $50 \%$ male) agreed to have physical activity assessed for three weeks. None of the children had a history of illness or current medication use. The experimental protocols were approved by the Institutional Review Board for Human Ethics and written parental consent was obtained for all children.

2.2. Procedures. Following recruitment, the children met with research staff in the early morning at school prior to the start of lessons. Baseline anthropometric measurements were taken on the first day, and the children were instructed as to the correct care and usage of the accelerometer. All children were asked to wear the accelerometer for three weeks with 9 of the possible 15 weekdays and 3 of the possible 6 weekend days randomly chosen for each child and used for the analyses.

2.3. Anthropometric Measurement. Body mass was determined barefoot and in light clothing with an accuracy of $0.1 \mathrm{~kg}$ using digital scales (Tanita TBF-401, Japan). Height was measured with an accuracy of $0.1 \mathrm{~cm}$ on a fixed stadiometer (Invicta 2007246, Leicester, UK). The children were assessed barefoot and placed in the Frankfort position. BMI was calculated as $\mathrm{kg} / \mathrm{m}^{2}$. Waist circumference was measured at the narrowest point between the bottom of the ribcage and the top of the iliac crest and taken at the end of expiration [14]. Hip circumference was measured at the level of the greater trochanters, where the buttocks protruded most [14]. Each circumference was taken twice and recorded to the nearest $0.1 \mathrm{~cm}$.

2.4. Measurement of Physical Activity. A triaxial accelerometer (RT3, StayHealthy Inc., USA) was used to assess physical activity. This small, light piezoelectric device is designed to detect accelerations in three axes and combine these to provide a triaxial vector magnitude count. The RT3 has been shown to be a valid and reliable device for assessing physical activity in Caucasian and Chinese children [1517]. Intermonitor variability, however, does exist [18], and in an attempt to counter this we ensured that each child used the same device throughout the measurement period (changed only if the device was not working satisfactorily). Additionally, before commencement and at the finish of each measurement day, every RT3 device was checked to determine the deviation in activity counts for each axis. Devices were passed if all axes were kept within \pm 5 counts, which ensured minimal Intermonitor variability. The study began with 40 RT3 devices, and four failed the Intermonitor variability check during the course of the study, leaving 36 devices by the end of the study. After the Intermonitor variability check, devices were initialized according to manufacturer specifications and set in the vector magnitude, 1s epoch mode. The RT3 was placed in a close-fitting bag, attached to a belt, and fastened firmly on the right hip, immediately superior to the iliac crest on the midaxilla line.

The children were asked to wear the device at school from 7.30 am until they returned home, which was usually $4.30 \mathrm{pm}$. On the weekend, they were asked to wear the device from the moment they got out of bed until when they went to bed in the evening. A daily monitoring period of 9 hours was delineated by the memory capacity of the accelerometer. To try to control wear time, we considered periods of consecutive zeros exceeding 60 minutes as nonwear time. Four children recorded a day with more than 60 minutes of consecutive zeros, and when asked about these periods they all reported taking the monitor off. The data for these days were rejected and replacement measurement days added.

Bouts of activity were identified using cluster identification [12]. This method involves using a series of algorithms to search for significant increases and decreases within the data series. These peaks and troughs are identified and classified. Identification and classification is based upon the threshold values which we have previously published [17], where nonactive behavior is defined as $<7.0 \mathrm{RT} 3_{\mathrm{vmag}} \cdot \mathrm{s}^{-1}$; low-intensity activity is defined as 7.0 to $<31 \mathrm{RT}_{\mathrm{vmag}}$. $\mathrm{s}^{-1}$, moderate intensity as $\geq 31$ to $<68.5 \mathrm{RT} 3_{\mathrm{vmag}} \cdot \mathrm{s}^{-1}$, and vigorous intensity activity is defined as $\geq 68.5 \mathrm{RT} 3_{\mathrm{vmag}} \cdot \mathrm{s}^{-1}$. A bout was, therefore, defined as a continuous segment whose element value was above $h$, the preset nonactive threshold 7.0 RT3 $3_{\mathrm{vmag}} \cdot \mathrm{s}^{-1}$. The duration of each bout was denoted as $T d$, and the duration of the nonactive interval between two adjacent bouts was denoted as Ti; the maximum element value or peak amplitude of an activity bout was denoted as Vp. A program was written in MatLab Version 7.0 (The MathWorks, Inc., USA) to process the data series in the manner explained. The variables computed by the program include the total number of bouts per day, mean duration of 
TABLE 1: The physical characteristics of the participants.

\begin{tabular}{lcc}
\hline & Lean $(n=42)$ & Obese $(n=42)$ \\
\hline Age $(\mathrm{y})$ & $8.58 \pm 0.45$ & $8.58 \pm 0.55$ \\
& $(7.97$ to 9.39$)$ & $(7.39$ to 9.57$)$ \\
Height $(\mathrm{cm})$ & $130.7 \pm 5.8$ & $133.2 \pm 5.1$ \\
& $(166.5$ to 144.2$)$ & $(121.2 \text { to } 144.0)^{*}$ \\
Body mass $(\mathrm{kg})$ & $26.8 \pm 3.6$ & $39.5 \pm 5.8$ \\
& $(19.7$ to 33.4$)$ & $(28.0 \text { to } 51.7)^{* *}$ \\
BMI $\left(\mathrm{kg} / \mathrm{m}^{2}\right)$ & $15.6 \pm 1.5$ & $22.2 \pm 2.5$ \\
& $(12.5$ to 18.0$)$ & $(18.5 \text { to } 28.3)^{* *}$ \\
Waist $(\mathrm{cm})$ & $55.9 \pm 3.0$ & $70.1 \pm 7.5$ \\
& $(50.2$ to 63.1$)$ & $(57.8 \text { to } 87.9)^{* *}$ \\
Hip $(\mathrm{cm})$ & $67.2 \pm 4.0$ & $81.0 \pm 5.9$ \\
& $(68.6$ to 73.5$)$ & $(58.6 \text { to } 94.5)^{* *}$ \\
\hline
\end{tabular}

Values are expressed as mean $\pm \mathrm{SD}$ (and range).

*significant difference between lean and obese, $P<.05$; ** significant difference between lean and obese, $P<.001$.

daily bouts in seconds (s), mean duration of the rest intervals between bouts in seconds (s), and the mean peak amplitude of daily bouts $\left(\mathrm{RT}_{\mathrm{vmag}} \cdot \mathrm{s}^{-1}\right)$. We also report the total minutes spent sedentary, in low, moderate, and vigorous activity for lean and obese. Data for the school days and home were computed separately.

2.5. Statistics. Descriptive characteristics (means and SD) were calculated for all key variables. Baseline anthropometric data were compared between the lean and obese using oneway analyses of variance. Factorial analyses of variance with repeated measures were used to determine the main effects of weight status (lean and obese), sex and location (school versus home) on activity pattern characteristics, and the variance in these activity pattern characteristics (expressed as the coefficient of variation). Interactions and main effects were deconstructed using analysis of simple main effects. Significance was set a priori at $P<.05$.

\section{Results}

Eighty-four children (42 lean and 42 obese) completed the anthropometric assessment. The physical characteristics of these children are presented in Table 1. There was no significant difference in age, although the obese were taller and heavier and had a greater waist and hip circumference compared to the lean.

Physical activity pattern characteristics derived from the bout identification algorithms are presented in Table 2. All 84 children completed the school-day monitoring, whilst 40 lean and 39 obese children completed the weekend monitoring. Factorial ANOVAs revealed significant main effects for location (school versus home) for the number of activity bouts $\left(F(1,75)=79.58 ; P<.001, \eta^{2} 0.515\right)$, the mean length of activity bouts $\left(F(1,75)=9.93 ; P<.01, \eta^{2}\right.$ $0.117)$, and the rest interval between bouts $(F(1,75)=21.76$; $P<.001, \eta^{2}$ 0.225). Followup analyses indicated that the number and length of activity bouts were greater at school than at home, whilst the rest intervals were longer at home compared to school (see Table 2).
A significant main effect for weight status was apparent for the number of activity bouts per day $(F(1,75)=38.48$; $\left.P<.001, \eta^{2} 0.275\right)$, with the lean engaging in more bouts of activity during school and at home in comparison to the obese $(P<.05)$. A significant main effect for weight status was also apparent for the duration of rest intervals between bouts $\left(F(1,75)=11.74 ; P<.01, \eta^{2} 0.135\right)$, with the obese taking longer rest intervals than the lean both at school and at home $(P<.05)$. There were no significant location by sex interactions for any variable, or weight status by sex, but there was a significant location by weight status interaction for the duration of the rest intervals between bouts $\left(F(1,75)=8.12 ; P<.05, \eta^{2} 0.098\right)$. Followup analyses showed that between-bout intervals were significantly longer in the obese and lean at home compared to school, but the difference between home and school was much more pronounced in the obese (see Table $2 ; P<.05$ ).

The mean minutes per day spent sedentary or in low, moderate, or vigorous physical activity are provided in Table 3. There was no main effects for weight status, sex, or location for the total minutes spent sedentary, engaged in low, moderate, or vigorous activity $(P>.05)$. Neither were there any interactions $(P>.05)$.

The intra-individual variation in day-to-day activity pattern characteristics are shown in Table 4. The factorial ANOVA revealed significant main effects for location for the variance in the number of activity bouts per day $(F(1.71)=$ 55.9; $\left.P<.001, \eta^{2} 0.441\right)$, the duration of bouts $(F(1.71)=$ 25.3; $\left.P<.001, \eta^{2} 0.263\right)$, interval between bouts of activity $\left(F(1.71)=82.9 ; P<.001, \eta^{2} 0.539\right)$, and bout intensity $\left(F(1.71)=13.5 ; P<.001, \eta^{2} 0.159\right)$. Followup analyses showed that variance increased at home compared to the school regardless of sex $(P<.05)$. The only interaction was for bout peak intensity, where a significant location by sex interaction was present $\left(F(1,71)=7.70 ; P<.01, \eta^{2} 0.098\right)$. Followup analyses showed that intra-individual variance in the peak intensity of activity bouts was constant in boys whether at school or at home $(P>.05)$. In girls, however, variance in the peak intensity of activity bouts increased significantly at home in comparison to school $(P<.05)$.

A significant main effect for sex in intra-individual variance existed for the mean duration of an activity bout $\left(F(1,71)=3.97 ; P<.05, \eta^{2} 0.053\right)$, where variance was greater in the girls $(P<.05)$. Similarly, significant main effect for sex in intra-individual variance in the peak intensity of an activity bout was apparent $(F(1,71)=14.22 ; P<.001$, $\left.\eta^{2} 0.167\right)$, with variance greater in the girls when at home $(P<.05)$.

Significant main effects for weight status were apparent in the intra-individual variance in the number of bouts per day $\left(F(1.71)=5.00 ; P<.05, \eta^{2} 0.066\right)$ and the rest interval between these activity bouts $\left(F(1,71)=6.1 ; P<.05, \eta^{2}\right.$ $0.079)$. In both cases, variance was higher in the obese than the lean $(P<.05)$.

\section{Discussion}

Free-living movement in children has been shown to comprise combinations of movements of varying intensities that 
TABLE 2: Activity pattern characteristics during school days and at the weekend in lean and obese Chinese children.

\begin{tabular}{|c|c|c|c|c|c|}
\hline & & Bouts per day & $\begin{array}{l}\text { Mean duration } \\
\text { of bouts (s) }\end{array}$ & $\begin{array}{l}\text { Mean duration of } \\
\text { between-bout } \\
\text { intervals (s) }\end{array}$ & $\begin{array}{l}\text { Mean peak intensity of } \\
\text { bouts }\left(\mathrm{RT} 3_{\mathrm{vmag}} \cdot \mathrm{s}^{-1}\right)\end{array}$ \\
\hline $\begin{array}{l}\text { Lean } \\
(n=42)\end{array}$ & Weekday & $961 \pm 150$ & $12.8 \pm 1.6$ & $23.7 \pm 8.5$ & $16.4 \pm 2.1$ \\
\hline $\begin{array}{l}\text { Obese } \\
(n=42)\end{array}$ & Weekday & $788 \pm 220^{* *}$ & $12.4 \pm 1.5$ & $38.5 \pm 26.7^{* *}$ & $15.2 \pm 1.7^{*}$ \\
\hline $\begin{array}{l}\text { Lean } \\
(n=40)\end{array}$ & Weekend & $677 \pm 218$ & $13.7 \pm 2.0$ & $47.0 \pm 32.2$ & $16.4 \pm 1.3$ \\
\hline $\begin{array}{l}\text { Obese } \\
(n=39)\end{array}$ & Weekend & $483 \pm 241^{* *}$ & $14.5 \pm 5.9$ & $134.2 \pm 167.8^{*}$ & $16.7 \pm 4.9$ \\
\hline
\end{tabular}

Values are expressed as mean $\pm \mathrm{SD}$.

RT3 intensity cutoffs ( $\mathrm{RT}_{\mathrm{vmag}} \cdot \mathrm{s}^{-1}$ ): sedentary $<7.0$; low intensity $\geq 7.0$ to $<31.0$; moderate intensity $\geq 31.0$ to $<68.5$; vigorous intensity $\geq 68.5$.

*significant difference between lean and obese, $P<.01$; ${ }^{*}$ significant difference between lean and obese, $P<.001$.

TABle 3: Total minutes per day sedentary, in low, moderate, and vigorous activity in lean and obese children by location.

\begin{tabular}{|c|c|c|c|c|c|}
\hline & & Sedentary $(\min )$ & $\begin{array}{l}\text { Low intensity } \\
(\min )\end{array}$ & $\begin{array}{c}\text { Moderate } \\
\text { intensity (min) }\end{array}$ & $\begin{array}{c}\text { Vigorous } \\
\text { intensity }(\mathrm{min})\end{array}$ \\
\hline $\begin{array}{l}\text { Lean } \\
(n=42)\end{array}$ & School & $429.6 \pm 33.3$ & $82.5 \pm 21.4$ & $23.9 \pm 7.8$ & $9.1 \pm 4.5$ \\
\hline $\begin{array}{l}\text { Obese } \\
(n=42)\end{array}$ & Home & $438.4 \pm 29.6$ & $76.7 \pm 20.5$ & $23.2 \pm 7.4$ & $7.7 \pm 3.1$ \\
\hline $\begin{array}{l}\text { Lean } \\
(n=40)\end{array}$ & School & $469.2 \pm 53.3$ & $51.5 \pm 30.3$ & $15.7 \pm 10.1$ & $8.1 \pm 2.7$ \\
\hline $\begin{array}{l}\text { Obese } \\
(n=39)\end{array}$ & Home & $484 \pm 83.7$ & $42.6 \pm 39.4$ & $13.8 \pm 13.2$ & $6.9 \pm 4.9$ \\
\hline
\end{tabular}

Values are expressed as mean \pm SD.

together form bouts of activity. These bouts have previously been found to be transient and largely composed of lowintensity walking [2]. The activity pattern characteristics that we report for the school day are remarkably similar to the previous observation studies $[2,3]$ in terms of the number of bouts per hour, the duration of the rest interval between bouts, and the intensity of bouts. The average physical activity bout length in our study of between 10 and $17 \mathrm{~s}$ corresponds well with Bailey et al.'s finding that $95 \%$ of children's physical activity bouts last less than $15 \mathrm{~s}$ [2]. Previous work using heart rate monitoring has already confirmed that children rarely sustain 10 - or 20 -minute bouts of moderate-intensity activity [19-21]. More recently, Stone et al. [22] demonstrated that even five-minute bouts of low-intensity activity are infrequent. The data from our study provide further evidence that children's free-living movement patterns are comprised of many, low-intensity, very short-duration bouts.

In contrast to the work of Stone et al. [22], we found that the length and intensity of activity bouts were similar in the lean and obese children, and these showed low intraindividual variation, regardless of location. We found that the intra-individual variance in activity pattern characteristics during school days were generally modest, varying from 9 to $15 \%$ in the lean and 8 and $26 \%$ in the obese. These are not dissimilar from previous findings of intra-individual variability in composite markers of physical activity, which are reported to be between 20 and $25 \%$ in children [9].
Less frequent movement bouts, coupled with longer rest periods, distinguished the obese from the lean. It is noteworthy that the length of time spent resting between bouts of movement shows the greatest intra-individual variation. At the weekend, the frequency of activity bouts declined in both the lean and obese, girls and boys alike. Similarly, the rest interval between movement bouts increased over the weekend in both the lean and obese, but this increase was substantially greater in the obese. This is the first study, to our knowledge, that has reported the variance in the duration of sedentary intervals between bouts of activity in lean and obese children, and our findings suggest that the amount of time spent resting between movement bouts appears to be a key characteristic differentiating lean from obese children. Obese adults have been found to sit for about 2 hours more than the lean [6], and our findings suggest that a similar, albeit less pronounced, difference may exist in lean and obese children. The cross-sectional design of the present study limits the ability to fully understand the relationship between rest intervals and weight status in the young, and experimental or longitudinal work is recommended.

Our findings have implications for the development of interventions. The likelihood of increasing aspects of physical activity that are uncommon in daily movement patterns, such as longer duration bouts of more intense physical activity, is probably poor. Similarly, aspects of physical activity that vary little within an individual are less likely to respond to intervention. Attention may be better 
TABLE 4: Intra-individual variation in the activity pattern characteristics at school and at home, by weight status and sex.

\begin{tabular}{llcccc}
\hline & & $\begin{array}{c}\text { Bouts per day }(\% \\
\text { CV })\end{array}$ & $\begin{array}{c}\text { Mean duration of } \\
\text { bouts }(\% \mathrm{CV})\end{array}$ & $\begin{array}{c}\text { Mean duration of rest } \\
\text { intervals (\% CV) }\end{array}$ & $\begin{array}{c}\text { Mean peak intensity of } \\
\text { bouts }(\% \text { CV })\end{array}$ \\
\hline Lean & Boys & $14.7 \pm 10.7$ & School & $9.6 \pm 6.8$ \\
$(n=42)$ & Girls & $13.4 \pm 8.0$ & $9.2 \pm 5.0$ & $24.9 \pm 13.9$ & $8.3 \pm 3.8$ \\
Obese & Boys & $15.5 \pm 9.8$ & $10.2 \pm 3.8$ & $17.6 \pm 8.4^{*}$ & $8.4 \pm 3.7$ \\
$(n=42)$ & Girls & $25.9 \pm 18.3$ & $11.5 \pm 3.9$ & $29.4 \pm 19.2$ & $11.8 \pm 4.2$ \\
\hline & & $12.3 \pm 4.2$ & $23.4 \pm 13.8^{*}$ & $9.6 \pm 5.6^{\#}$ \\
\hline Lean & Boys & $37.9 \pm 29.4^{*}$ & $16.1 \pm 14.3^{\#}$ & $52.6 \pm 38.3$ & $19.7 \pm 15.4^{*}$ \\
$(n=40)$ & Girls & $40.6 \pm 32.5$ & $23.1 \pm 19.2$ & $57.8 \pm 34.4^{*}$ & $11.0 \pm 4.5^{\#}$ \\
Obese & Boys & $54.8 \pm 31.0^{*}$ & $17.4 \pm 11.2^{\#}$ & $78.9 \pm 43.0$ & $18.4 \pm 13.0^{*}$ \\
\hline
\end{tabular}

Values are expressed as mean \pm SD. CV: coefficient of variation.

* significant difference between lean and obese, $P<.05$; ${ }^{\#}$ significant difference between boys and girls, $P<.05$.

focused upon decreasing the periods of rest between bouts of movement and increasing the number of short-duration bouts of movement per day.

The primary limitation of this study is the relatively small sample which may increase the chance of type II errors. The data are also restricted to 7-9-year-old Hong Kong Chinese children, and this may limit the generalisability of the findings. It is notable that our primary findings are similar to those of Bailey et al. [2]; however, direct comparisons of our findings to other data sets are challenging because data collection approaches are not uniform. The advent of more sophisticated and affordable monitoring tools, such as triaxial accelerometers with high sampling rates and large memory capacity, will certainly improve this situation and should encourage greater harmonization of accelerometry methodology. We choose not to assess the physical activity patterns at home during the weekday because we felt Hong Kong children were less likely to be active at this time given the homework that is completed during the week; however, these data may provide valuable information about the interplay between movement bouts and inactivity during periods of likely high sedentary behavior and should be considered in future studies.

\section{Conclusion}

To conclude, this study has shown that, similar to previous findings, Chinese children engage in many predominantly low-intensity bouts of short-duration activity. Small lifestyle changes are quite likely to have considerable impact on activity pattern characteristics and identifying the biological and environmental (both physical and sociocultural) antecedents of this pattern of movement is an important next step. The obese child engages in fewer activity bouts and takes longer rest intervals between bouts, both during the school day and at home. As the prevalence of obesity continues to rise, efforts should also be directed toward understanding the consequences of extended rest periods between bouts of movement and fewer movement bouts a day, as well as finding ways to reverse these.

\section{Acknowledgment}

The authors are grateful to The University of Hong Kong Research Council Strategic Research Theme Public Health and Seed Funding Program for Basic Research for supporting this project.

\section{References}

[1] A. M. McManus, "Physical activity-a neat solution to an impending crisis," Journal of Sports Science and Medicine, vol. 6, no. 3, pp. 368-373, 2007.

[2] R. C. Bailey, J. Olson, S. L. Pepper, J. Porszasz, T. J. Barstow, and D. M. Cooper, "The level and tempo of children's physical activities: an observational study," Medicine and Science in Sports and Exercise, vol. 27, no. 7, pp. 1033-1041, 1995.

[3] N. Berman, R. Bailey, T. J. Barstow, and D. M. Cooper, "Spectral and bout detection analysis of physical activity patterns in healthy, prepubertal boys and girls," American Journal of Human Biology, vol. 10, no. 3, pp. 289-297, 1998.

[4] E. Baraldi, D. M. Cooper, S. Zanconato, and Y. Armon, "Heart rate recovery from 1 minute of exercise in children and adults," Pediatric Research, vol. 29, no. 6, pp. 575-579, 1991.

[5] M. R. Stone, A. V. Rowlands, and R. G. Eston, "Characteristics of the activity pattern in normal weight and overweight boys," Preventive Medicine, vol. 49, no. 2-3, pp. 205-208, 2009.

[6] J. A. Levine, S. K. Mecrady, L. M. Lanningham-Foster, P. H. Kane, R. C. Foster, and C. U. Manohar, "The role of free-living daily walking in human weight gain and obesity," Diabetes, vol. 57, no. 3, pp. 548-554, 2008.

[7] G. J. Norman, B. A. Schmid, J. F. Sallis, K. J. Calfas, and K. Patrick, "Psychosocial and environmental correlates of adolescent sedentary behaviors," Pediatrics, vol. 116, no. 4, pp. 908-916, 2005.

[8] A. V. Rowlands, "Methodological approaches for investigating the biological basis for physical activity in children," Pediatric Exercise Science, vol. 21, no. 3, pp. 273-278, 2009.

[9] E. E. Wickel, J. C. Eisenmann, R. P. Pangrazi et al., "Do children take the same number of steps every day?" American Journal of Human Biology, vol. 19, no. 4, pp. 537-543, 2007.

[10] M. S. Buchowski, S. Acra, K. M. Majchrzak, M. Sun, and K. Y. Chen, "Patterns of physical activity in free-living adults in the Southern United States," European Journal of Clinical Nutrition, vol. 58, no. 5, pp. 828-837, 2004. 
[11] T. J. Wilkin, K. M. Mallam, B. S. Metcalf, A. N. Jeffery, and L. D. Voss, "Variation in physical activity lies with the child, not his environment: evidence for an 'activity stat' in young children (EarlyBird 16)," International Journal of Obesity, vol. 30, no. 7, pp. 1050-1055, 2006.

[12] J. D. Veldhuis and M. L. Johnson, "Cluster analysis: a simple, versatile, and robust algorithm for endocrine pulse detection," American Journal of Physiology, vol. 250, no. 4, pp. E486-E493, 1986.

[13] T. J. Cole, M. C. Bellizzi, K. M. Flegal, and W. H. Dietz, "Establishing a standard definition for child overweight and obesity worldwide: international survey," British Medical Journal, vol. 320, no. 7244, pp. 1240-1243, 2000.

[14] M. Marfell-Jones, T. Olds, A. Stewart, and L. Carter, "International standards for anthropometric assessment," ISAK: Potchefstroom, South Africa 2006, http://www.isakonline .com/publications.html.

[15] A. V. Rowlands, P. W. M. Thomas, R. G. Eston, and R. Topping, "Validation of the RT3 triaxial accelerometer for the assessment of physical activity," Medicine and Science in Sports and Exercise, vol. 36, no. 3, pp. 518-524, 2004.

[16] S. M. Powell and A. V. Rowlands, "Intermonitor variability of the RT3 accelerometer during typical physical activities," Medicine and Science in Sports and Exercise, vol. 36, no. 2, pp. 324-330, 2004.

[17] E. Y. W. Chu, A. M. McManus, and C. C. W. Yu, "Calibration of the RT3 accelerometer for ambulation and nonambulation in children," Medicine and Science in Sports and Exercise, vol. 39, no. 11, pp. 2085-2091, 2007.

[18] S. M. Powell, D. I. Jones, and A. V. Rowlands, "Technical variability of the RT3 accelerometer," Medicine and Science in Sports and Exercise, vol. 35, no. 10, pp. 1773-1778, 2003.

[19] N. Armstrong, J. R. Williams, J. Balding, P. Gentle, and B. J. Kirby, "Cardiopulmonary fitness, physical activity patterns and selected coronary risk factor variables in 11- to 16- year olds," Pediatric Exercise Science, vol. 3, pp. 219-228, 1991.

[20] N. Armstrong, B. J. Kirby, A. M. McManus, and J. R. Welsman, "Physical activity patterns and aerobic fitness among prepubescents," European Physical Education Review, vol. 2, pp. 19-29, 1996.

[21] A. M. McManus, "The influence of vehicular traffic upon physical activity in children," Journal of Human Biology, vol. 14, pp. 159-163, 2006.

[22] M. R. Stone, A. V. Rowlands, A. R. Middlebrooke, M. N. Jawis, and R. G. Eston, "The pattern of physical activity in relation to health outcomes in boys," International Journal of Pediatric Obesity, vol. 4, no. 4, pp. 306-315, 2009. 


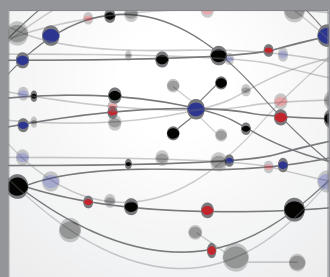

The Scientific World Journal
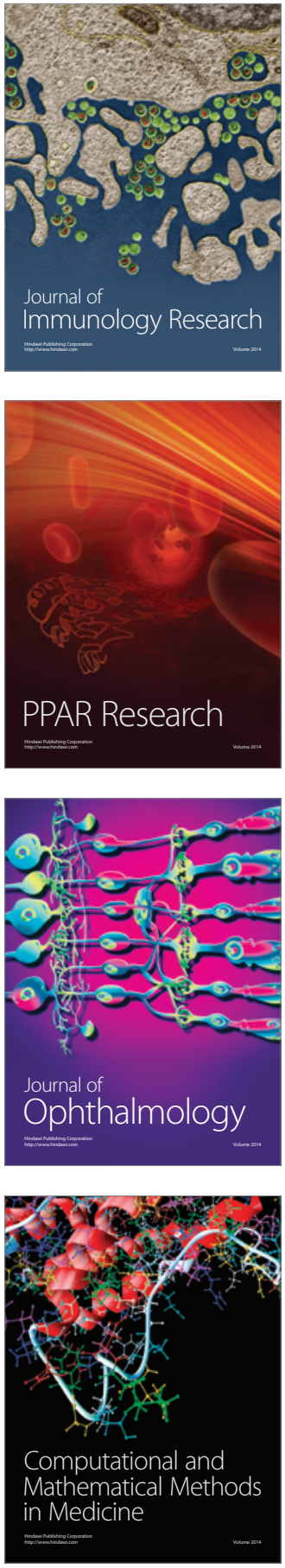

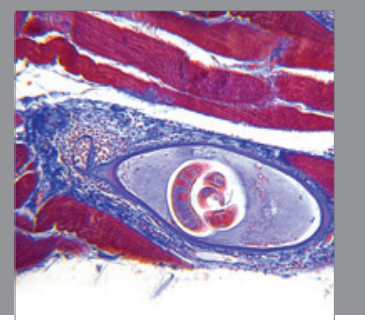

Gastroenterology

Research and Practice
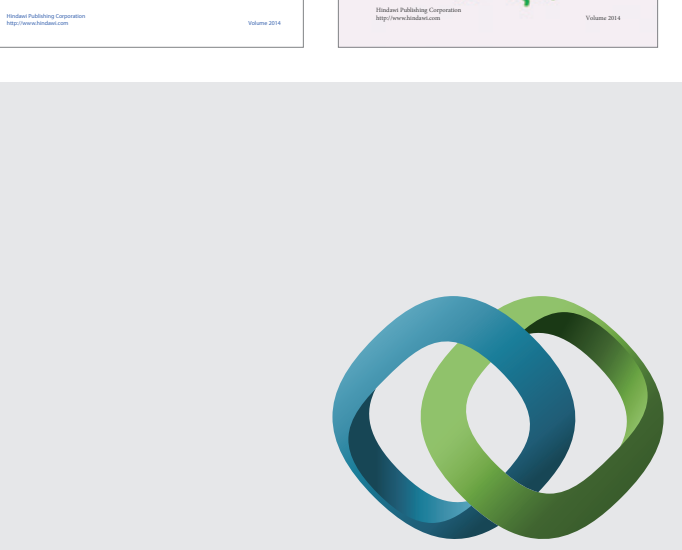

\section{Hindawi}

Submit your manuscripts at

http://www.hindawi.com
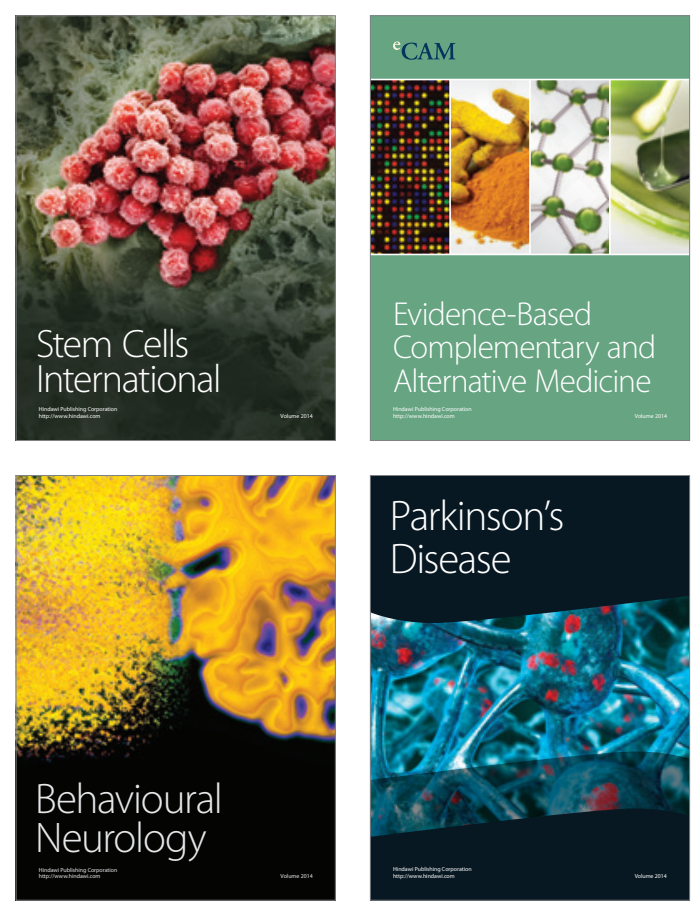

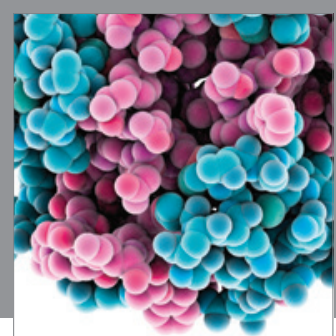

Journal of
Diabetes Research

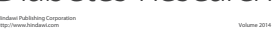

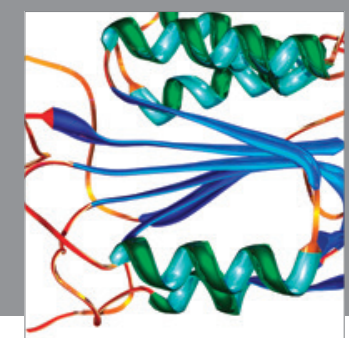

Disease Markers
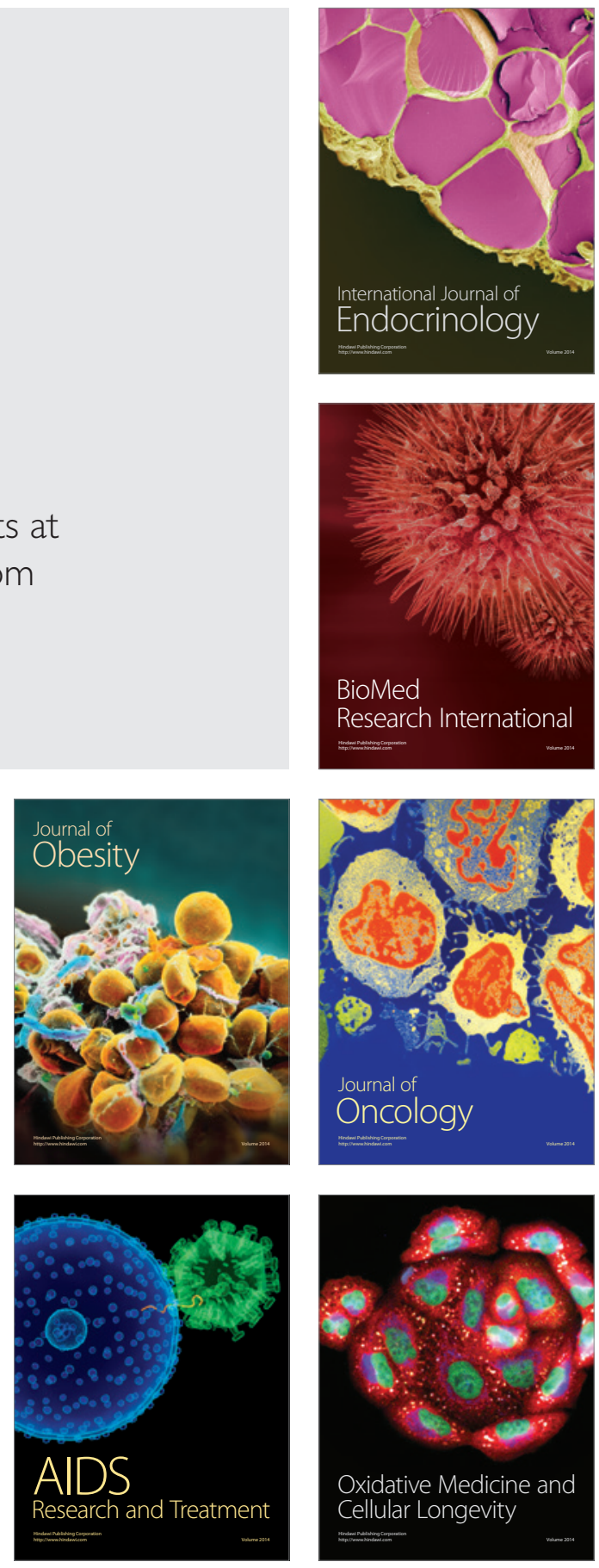